\title{
Both structural damage and inflammation of the lumbar spine contribute to the sagittal imbalance in ankylosing spondylitis patients with thoracolumbar kyphosis
}

\author{
Song Li, Chang-Zhi Du, Sai-Hu Mao, Ben-Long Shi, Ze-Zhang Zhu, Yong Qiu \\ Department of Spine Surgery, the Affiliated Drum Tower Hospital of Nanjing University Medical School, Nanjing, China \\ Correspondence to: Sai-Hu Mao, MD; Ze-Zhang Zhu, MD. Department of Spine Surgery, Drum Tower Hospital of Nanjing University Medical \\ School, Zhongshan Road 321, Nanjing, China. Email: siemens_636@163.com; ze_zhangzhu@sina.com@sina.com.
}

\begin{abstract}
Background: The relationship between structural damage and inflammation of the spine and the sagittal imbalance in ankylosing spondylitis (AS) is not well understood. The present study aimed to investigate the correlation between structural damage and inflammation of the lumbar spine and the sagittal imbalance in AS patients with thoracolumbar kyphosis.
\end{abstract}

Methods: Forty-five AS patients with thoracolumbar kyphosis were retrospectively reviewed. Six sagittal spinal parameters, including the C7 tilt (C7T), spino-sacral angle (SSA), global kyphosis (GK), the sagittal vertical axis (SVA), thoracic kyphosis (TK), and lumbar lordosis (LL), were measured. Structural damage of the lumbar spine was assessed by the modified Stoke AS Spine Score (mSASSS) on radiographs. Lumbar spinal inflammation was evaluated by the AS spinal magnetic resonance imaging (MRI) activity (ASspiMRI-a) on MRI. Correlation analysis was performed using the paired sample $t$-test. Multivariable linear regression models were constructed to analyze the contributions of mSASSS and ASspiMRI-a to the sagittal parameters. Results: The average values of the sagittal parameters C7T, SSA, GK, SVA, TK, and LL were $68.1^{\circ}$, $80.1^{\circ}, 77.3^{\circ}, 168.7 \mathrm{~mm}, 47.7^{\circ}$, and $-0.7^{\circ}$, respectively. The average mSASSS and ASspiMRI-a scores were 9.8 and 10.8, respectively. Correlation analysis showed that the mSASSS and ASspiMRI-a were correlated with C7T, SSA, SVA, and LL (the Spearman correlation coefficients were $-0.439,-0.390,0.424$, and 0.530 for mSASSS; $-0.406,-0.402,0.378$, and 0.486 for ASspiMRI-a; $\mathrm{P}<0.05)$. The C7T, SSA, and SVA were significantly correlated with $\mathrm{LL}(\mathrm{r}=-0.696,-0.779$, and 0.633 , respectively; $\mathrm{P}<0.05)$. There was a weak correlation between the mSASSS and ASspiMRI-a $(\beta=0.299, \mathrm{P}=0.046)$. The multivariable regression models indicated that the sagittal imbalance was determined to a greater extent by the mSASSS than ASspiMRI-a (the $\beta$ values were $-1.550 v s$. -0.649 for C7T, $-1.865 v s$. -1.231 for SSA, 9.161 vs. 3.823 for SVA, and $3.128 v s$. 1.717 for LL).

Conclusions: Both structural damage and inflammation of the lumbar spine contributed to the sagittal imbalance in AS patients with thoracolumbar kyphosis. In the late stages of AS, the sagittal imbalance was more attributable to the structural damage than the inflammation of the lumbar spine.

Keywords: Ankylosing spondylitis (AS); thoracolumbar kyphosis; sagittal imbalance; mSASSS; ASspiMRI-a

Submitted Nov 24, 2019. Accepted for publication Sep 22, 2020.

doi: 10.21037/qims-19-990

View this article at: http://dx.doi.org/10.21037/qims-19-990 


\section{Introduction}

Ankylosing spondylitis (AS) is a chronic systemic disease that primarily causes inflammation and structural damage to the sacroiliac joints and spine (1). In the early stages of AS, patients suffer from sacroiliitis, spondylitis, spondylodiscitis, and spondyloarthritis $(2,3)$. In the late stages, AS patients often develop a progressive ossification of spinal ligaments and facet joints, leading to fixed thoracolumbar kyphosis $(4,5)$.

Previous studies have shown that both inflammation and structural damage of the sacroiliac joints and spine constitute the initial causes of AS damage, irrespective of the stage a patient is in (6-8). In AS patients with longstanding disease, chronic spinal inflammation, and structural damage causes a loss of the normal thoracic and lumbar curves, leading to severe sagittal imbalance $(5,9)$. Landewé et al. (10) and Machado et al. (11) found that both spinal inflammation and structural damage gradually resulted in the functional and spinal mobility impairments in AS patients. These secondary impairments were found to be significantly correlated with the spinal inflammation and structural damage in their series $(10,11)$. However, the inflammation and structural damage of the spine, especially the lumbar spine, on the sagittal alignments of AS patients with thoracolumbar kyphosis, is still unclear. Hence, the purpose of this study was to analyze the correlations between structural damage and inflammation of the lumbar spine and the sagittal imbalance in AS patients with thoracolumbar kyphosis, while taking other possible factors including disease severity, demographic characteristics, and laboratory tests into account.

\section{Methods}

AS patients with fixed thoracolumbar kyphosis who underwent lumbar osteotomy in our center from January 2004 to December 2010 were retrospectively reviewed. The ethics committee approved this study of the Affiliated Drum Tower Hospital of Nanjing University Medical School. The inclusion criteria were as follows: (I) the diagnosis met the modified New York criteria for AS (12); (II) patients had preoperative standing radiographs of the entire spine and magnetic resonance imaging (MRI) of the sagittal lumbar spine; (III) disease duration $>3$ years; and (IV) laboratory tests including erythrocyte sedimentation rate (ESR), C-reactive protein (CRP), and human leukocyte antigen-B27 (HLA-B27) were available. Patients with spinal fractures, pseudarthrosis, and those who had undergone previous spinal surgery were excluded. In total, 45 AS patients were included in this study. There were 40 males and five females with an average age of $35.8 \pm 9.5$ years (range, $17-57$ years) and mean disease duration of $9.0 \pm 5.3$ years (range, $3-15$ years).

\section{Assessment of disease severity}

Disease activity was assessed using the Bath Ankylosing Spondylitis Disease Activity Index (BASDAI, range 0-100), which is a traditional scoring system widely utilized for the evaluation of disease activity in AS patients, and was already in use at our clinic. It was a self-administered questionnaire related to the particular symptoms of the disease, including fatigue/tiredness, axial pain, joint swelling, discomfort in enthuses, stiffness severity, and duration (13). Also, the Bath Ankylosing Spondylitis Functional Index (BASFI, range $0-100)$ was used. This is a self-reported measurement to assess patients' perceived level of function during daily activities and physical function (14). Additionally, painrelated disability was assessed using the Oswestry Disability Index (ODI, range 0-100), a disease-specific measurement consisting of 10 items (15).

\section{Assessment of sagittal imbalance}

The following spinal parameters were measured on the upright lateral image obtained with the patient standing, using a distance of $183 \mathrm{~cm}, 125 \mathrm{kVp}$, photo-timed exposure: (I) C7 tilt (C7T) (5), which is defined as the angle between the line joining the center of the $\mathrm{C} 7$ vertebra and the center of the sacral endplate and the horizontal plane (Figure 1A); II) spino-sacral angle (SSA) (16), which is subtended by the angle between the line connecting the center of the C7 vertebra to the midpoint of the sacral endplate and the sacral endplate (Figure 1A); (III) global kyphosis (GK) (17), which is measured as the angle between the upper endplate of the maximally tilted upper-end vertebra and the inferior endplate of the maximally tilted lower end vertebra (Figure 1A); (IV) sagittal vertical axis (SVA) $(18,19)$, which is represented by the distance between the $\mathrm{C} 7$ plumb line and superior posterior corner of S1. SVA was considered positive if the plumb line fell anterior to the postero-superior corner of $\mathrm{S} 1$ and was considered negative if the plumb line fell behind the postero-superior corner of S1 (Figure 1A); (V) thoracic kyphosis (TK) (20), which is defined as the angle between the superior endplate of the T5 vertebra and the 

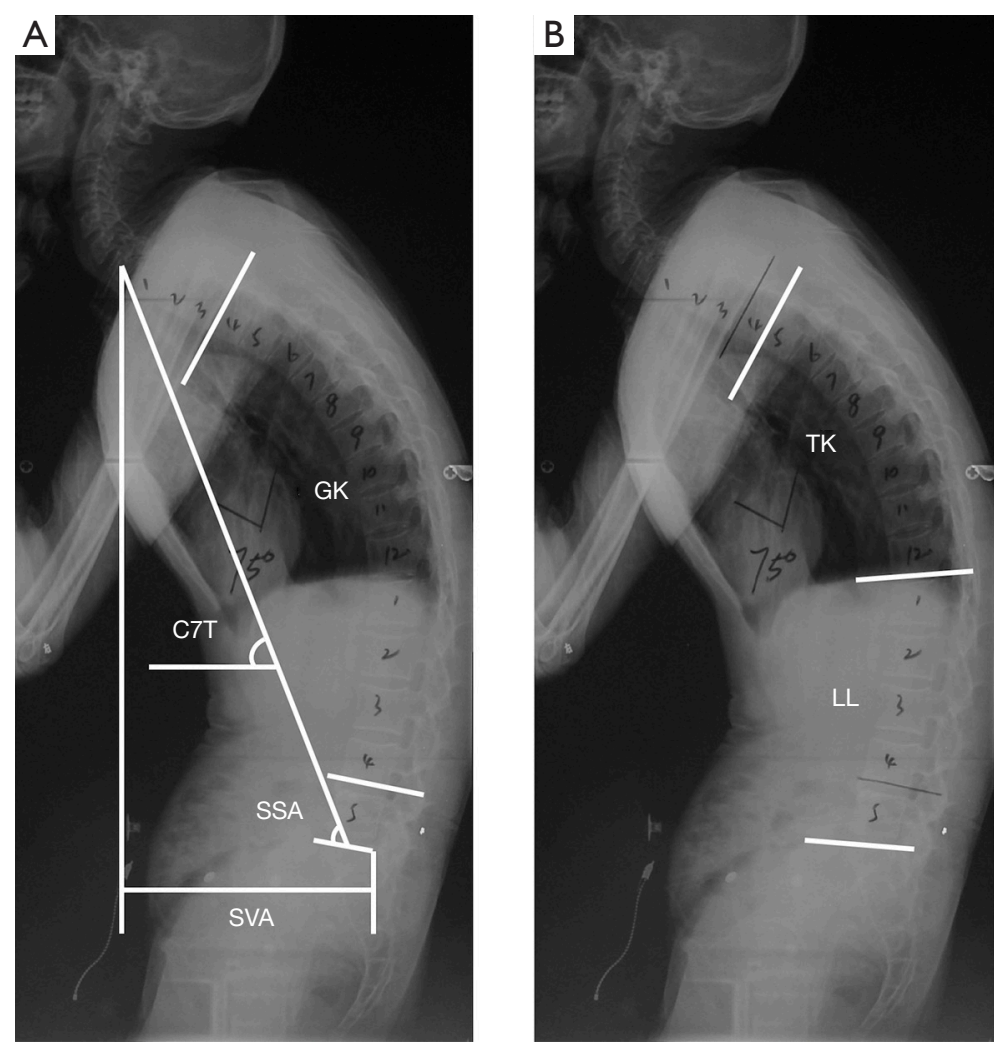

Figure 1 Spinal parameters measured on the lateral radiographs. (A) C7T: the angle between the line joining the center of the C7 vertebra and the center of the sacral endplate and the horizontal plane; SSA: the angle between the line connecting the C7 vertebra to the midpoint of the sacral endplate and the sacral endplate; GK: the angle between the upper endplate of the maximally tilted upper end vertebra and the inferior endplate of the maximally tilted lower end vertebra; SVA: the distance between the C7 plumb line and the posterior superior corner of S1. (B) TK: the angle between the superior endplate of the T5 vertebra and the inferior endplate of the T12 vertebra; LL: the angle between the inferior endplate of the T12 vertebra and the endplate of S1.

inferior endplate of the T12 vertebra (Figure 1B); and (VI) lumbar lordosis (LL) $(18,21)$, which is assessed as the angle between the inferior endplate of the T12 vertebra and the endplate of S1. Lordosis was defined as negative and kyphosis as positive for LL (Figure 1B). Two qualified and well-trained readers ( $\mathrm{ZC}$ and $\mathrm{LB}$ ) who were blinded to the patient's identity and treatment evaluated each radiograph independently. The mean values of the parameters measured by the two readers were adopted in the analysis.

\section{Scoring system}

The modified Stoke AS Spine Score (mSASSS) system (22) was used to assess the structural damage on the lateral $\mathrm{X}$-ray radiographs. A total of 12 anterior corners were assessed, including the lower border of the T12 vertebra, the upper and lower borders of all five lumbar vertebrae, and the upper border of S1. Each corner was scored as follows: $0=$ normal; $1=$ erosion, sclerosis, and squaring; $2=$ syndesmophyte; and $3=$ bony bridging (22). The sum of the numerical scores was recorded as the total mSASSS, and the scores ranged from 0 to 36 .

The inflammation of the lumbar spine was scored according to the AS spinal MRI activity (ASspiMRI-a) scoring system (23). The MRI scan was performed using a 1.5-Tesla MRI Achieva scanner (Philips Medical Systems, Best, The Netherlands), and images were assessed using the PACS client software (Easy Vision IDS5, version 11.4, Philips, Hamburg, Germany). The sagittal orientation sequences were the fat-saturated short tau inversion recovery (STIR) and the T1-weighted Turbo Spin-Echo (TSE) $(24,25)$. Inflammatory activity was assessed at the level of the disco-vertebral unit (DVU), which was defined as the area between the two horizontal lines crossing 

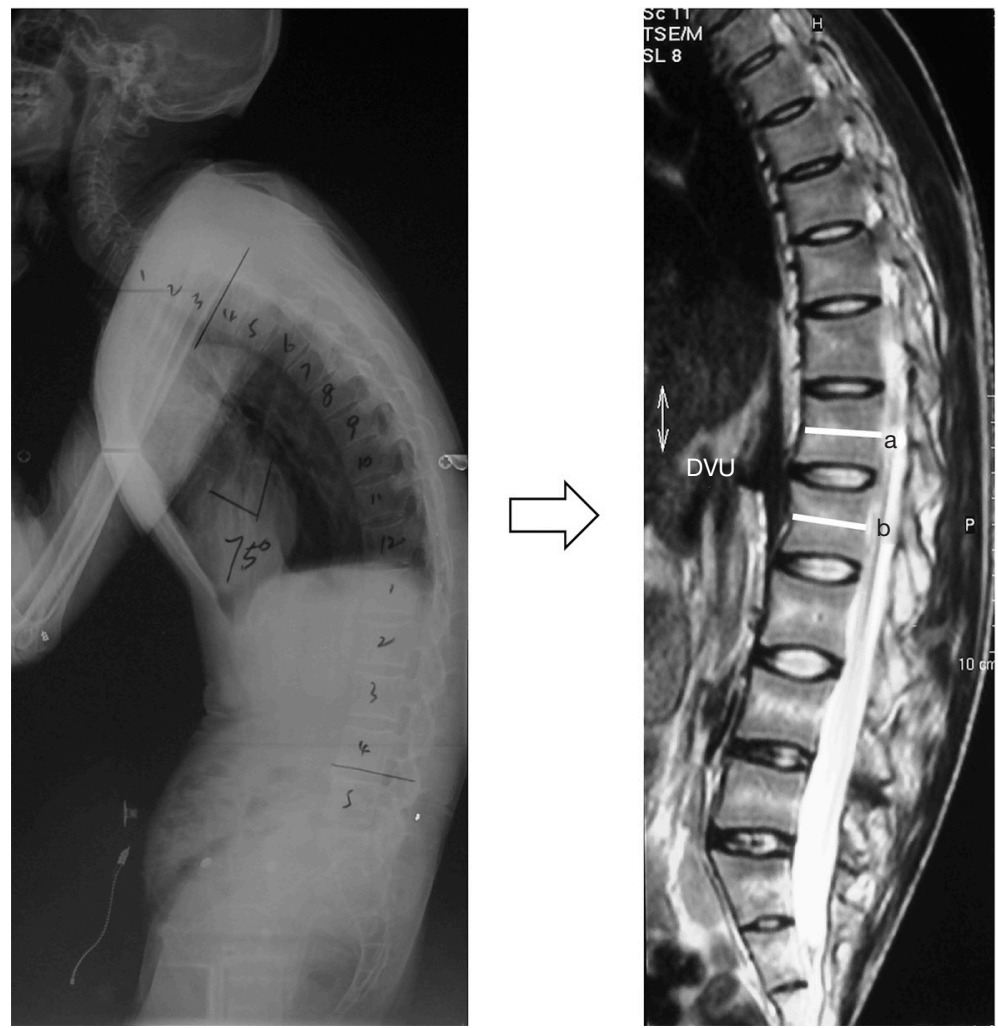

Figure 2 A DVU referred to the area between line a and line b. Lines a and b were defined as the horizontal lines bisecting two adjacent vertebrae. DVU, disco-vertebral unit.

the middle of two adjacent vertebrae on sagittal MRI (Figure 2) (23). Each DVU was scored as follows: 0= normal; $1=$ minor $(\leq 1 / 4)$ bone marrow edema $(\mathrm{BME})$ of each DVU or relevant changes; $2=$ moderate $(>1 / 4$ but $\leq 1 / 2) \mathrm{BME}$ or enhancement; $3=$ major $(>1 / 2) \mathrm{BME}$ or enhancement of the DVU; $4=$ minor $(\leq 1 / 4)$ erosion with BME; $5=$ moderate $(>1 / 4$ but $\leq 1 / 2)$ erosion with BME; and $6=$ major $(>1 / 2)$ erosion of the DVU (23). Six DVUs from the T12 to S1 were assessed for each AS patient, and the total ASspiMRI-a scores ranged from 0 to 36 . Two qualified and well-trained readers ( $Z C$ and $L B)$, different from the readers of the radiographs, who were blinded to the patient's identity and treatment, evaluated each image independently. The mean values of the scores assessed by the two readers were adopted in the analysis.

\section{Statistical analysis}

Data were statistically analyzed using the SPSS software 17.0 (SPSS, Inc., USA). Descriptive statistics were used to analyze patients' demographic parameters. Correlation analysis was performed using the paired sample $t$-test, and the Spearman correlation coefficients were calculated. Additionally, multivariable linear regression models were constructed to analyze the contributions of the mSASSS and ASspiMRI-a to the sagittal parameters. A statistically significant difference was defined as $\mathrm{P}<0.05$.

\section{Results}

The average scores of BASDAI, BASFI, and ODI were $29.0 \pm 16.1,28.5 \pm 20.0$, and $28.2 \pm 16.3$. The average ESR and CRP values were $24.8 \pm 15.3 \mathrm{~mm} / \mathrm{h}$ and $14.2 \pm 23.7 \mathrm{mg} / \mathrm{L}$ (Table 1). The global spinal parameters, including C7T, SSA, GK, and SVA were $68.1^{\circ} \pm 11.7^{\circ}, 80.1^{\circ} \pm 18.7^{\circ}$, $77.3^{\circ} \pm 21.4^{\circ}$, and $168.7 \pm 74.3 \mathrm{~mm}$, respectively, while the local parameters, including TK and LL, were $47.7^{\circ} \pm 16.7^{\circ}$ and $-0.7^{\circ} \pm 22.7^{\circ}$, respectively (Table 2 ). The average mSASSS and ASspiMRI-a scores were $9.8 \pm 3.5$ and 10.8 \pm 4.6 , respectively, and all AS patients had elevated mSASSS and ASspiMRI-a scores (the scores of mSASSS and ASspiMRI-a $>0$ for all patients). 
Table 1 Summary of the demographic, clinical, and imaging characteristics in AS patients with thoracolumbar kyphosis $(n=45)$

\begin{tabular}{lc}
\hline Characteristics & Value $^{*}$ \\
\hline Age (years) & $35.8 \pm 9.5[17-57]$ \\
Gender (\% of males) & 89.6 \\
HLA-B27 positive (\%) & 95.8 \\
Disease duration (years) & $9.0 \pm 5.3[3-15]$ \\
BASDAI & $29.0 \pm 16.1[3-79]$ \\
BASFI & $28.5 \pm 20.0[4.5-57]$ \\
ODI & $28.2 \pm 16.3[4-52]$ \\
ESR (mm/h) & $24.8 \pm 15.3[5-92]$ \\
CRP (mg/L) & $14.2 \pm 23.7[0.2-128.4]$ \\
mSASSS & $9.8 \pm 3.5[4-28]$ \\
ASspiMRI-a & $10.8 \pm 4.6[3-20]$ \\
\hline
\end{tabular}

*, values are shown as mean \pm SD [range]. BASDAI, Bath Ankylosing Spondylitis Disease Activity Index; BASFI, Bath Ankylosing Spondylitis Functional Index; ODI, Oswestry Disability Index; ESR, erythrocyte sedimentation rate; CRP, C-reactive protein; mSASSS, modified Stoke Ankylosing Spondylitis Spine Score; ASspiMRI-a, Ankylosing Spondylitis spinal MRI activity.

\section{Correlation analysis}

The mSASSS was correlated with the local parameter (LL) and global parameters including C7T, SSA, and SVA $(\mathrm{r}=0.530,-0.439,-0.390$, and 0.424 , respectively, $\mathrm{P}<0.05)$. However, correlations between the mSASSS and the other sagittal parameters were not observed $(\mathrm{P}>0.05)$ (Table 3).

Correlations were also observed between the ASspiMRI-a and the sagittal parameters, including C7T, SSA, SVA, and LL ( $\mathrm{r}=-0.406,-0.402,0.240$, and 0.486, respectively, $\mathrm{P}<0.05)$. However, the ASspiMRI-a was not correlated with GK and TK $(\mathrm{P}>0.05)$ (Table 3).

The correlation analysis also showed that C7T, SSA, and SVA were significantly correlated with LL ( $\mathrm{r}=-0.696$, -0.779 , and 0.633 , respectively, $\mathrm{P}<0.05$, Table 4).

\section{Multivariable linear regression models}

Interactions between the sagittal parameters and the other possible factors, including age, gender, disease duration, BASDAI, BASFI, ODI, ESR, CRP, and HLA-B27, were tested and excluded. When taking the mSASSS and

Table 2 Radiographic assessments of the sagittal imbalance in AS patients with thoracolumbar kyphosis

\begin{tabular}{lcccccc}
\hline & $\mathrm{C7T}\left({ }^{\circ}\right)$ & $\mathrm{SSA}\left({ }^{\circ}\right)$ & GK $\left({ }^{\circ}\right)$ & SVA $(\mathrm{mm})$ & TK $\left(^{\circ}\right)$ & LL $\left(^{\circ}\right)$ \\
\hline Mean \pm SD & $68.1 \pm 11.7$ & $80.1 \pm 18.7$ & $77.3 \pm 21.4$ & $168.7 \pm 74.3$ & $47.7 \pm 16.7$ & $-0.7 \pm 22.7$ \\
$95 \% \mathrm{Cl}$ & 64.6 to 71.4 & 74.9 to 85.7 & 71.1 to 83.3 & 145.8 to 191.2 & 43.0 to 52.4 & -7.1 to 6.0 \\
\hline
\end{tabular}

SD, standard deviation; Cl, confidence interval; C7T, C7 tilt; SSA, spino-sacral angle; GK, global kyphosis; SVA, sagittal vertical axis; TK, thoracic kyphosis; LL, lumbar lordosis.

Table 3 Correlation between sagittal parameters and mSASSS/ASspiMRI-a in AS patients with thoracolumbar kyphosis

\begin{tabular}{lccccc}
\hline Parameters & C7T & SSA & GK & SVA & TK \\
\hline mSASSS & & & & & \\
Coefficient & $-0.439^{*}$ & $-0.390^{*}$ & -0.01 & $0.424^{*}$ & 0.12 \\
P value & 0.003 & 0.008 & 0.997 & 0.004 & 0.939 \\
ASspiMRI-a & & & & 0.000 \\
Coefficient & $-0.406^{*}$ & $-0.402^{*}$ & 0.240 & $0.378^{*}$ & 0.057 \\
P value & 0.006 & 0.006 & 0.112 & 0.01 & $0.486^{*}$ \\
\hline
\end{tabular}

*, P<0.05. C7T, C7 tilt; SSA, spino-sacral angle; GK, global kyphosis; SVA, sagittal vertical axis; TK, thoracic kyphosis; LL, lumbar lordosis; mSASSS, modified Stoke Ankylosing Spondylitis Spine Score; ASspiMRI-a, Ankylosing Spondylitis spinal MRI activity. 
Table 4 Correlation between LL and C7T/SSA/SVA in AS patients with thoracolumbar kyphosis

\begin{tabular}{lccc}
\hline LL & C7T & SSA & SVA \\
\hline Coefficient & -0.696 & -0.779 & 0.633 \\
P value & $<0.001$ & $<0.001$ & $<0.001$ \\
\hline
\end{tabular}

LL, lumbar lordosis; C7T, C7 tilt; SSA, spino-sacral angle; SVA, sagittal vertical axis.

ASspiMRI-a as independent variables and the sagittal parameters (including C7T, SSA, SVA, and LL) as dependent variables, both the mSASSS and ASspiMRI-a determined the four sagittal spinal parameters $(\mathrm{P}<0.05$, Table 5). Notably, the sagittal imbalance was determined to a greater extent by mSASSS than ASspiMRI-a (the $\beta$ values were -1.550 vs. -0.649 for C7T, -1.865 vs. -1.231 for SSA, 9.161 vs. 3.823 for SVA, and 3.128 vs. 1.717 for LL).

\section{Discussion}

In the advanced stages of AS, patients often suffer from fixed thoracolumbar kyphosis $(17,26)$. The gradually increased thoracic kyphosis and decreased lumbar lordosis eventually lead to the rigid global sagittal imbalance $(17,27,28)$. Crucially, this sagittal imbalance is not merely a cosmetic and psychological disturbance (26). The severely inefficient posture ultimately leads to the inability to look straight ahead and a dramatic restriction of walking and limitation in interpersonal communications $(17,29)$.

Recently, several investigations have found that spinal inflammation and structural damage were two vital biomechanisms of AS impairments $(11,18)$. According to the baseline and 2-year data of the Outcome in Ankylosing Spondylitis International Study (OASIS) (217 AS patients), Landewé et al. concluded that the functional impairment in AS patients were independently influenced by both the patientreported disease activity and the level of structural damage of the lumbar and cervical spine (10). Additionally, Machado et al. investigated 214 AS patients from the Ankylosing Spondylitis Study for the Evaluation of Recombinant Infliximab Therapy cohort. They suggested that the spinal mobility impairment in AS patients was independently caused by the irreversible spinal damage and the reversible spinal inflammation (11). In early AS, spinal mobility impairment was more attributable to spinal inflammation, whereas structural damage was the primary cause of impairment in late disease. Similarly, we hypothesized that the fixed sagittal imbalance in late AS
Table 5 Results of the multivariable regression analysis in AS patients with thoracolumbar kyphosis

\begin{tabular}{lcccc}
\hline Parameters & C7T & SSA & SVA & LL \\
\hline mSASSS & & & & \\
$\mathrm{B}^{*}$ & -1.550 & -1.865 & 9.161 & 3.128 \\
P value & 0.001 & 0.018 & 0.003 & $<0.001$ \\
ASspiMRI-a & & & & \\
$\mathrm{B}^{*}$ & -0.649 & -1.231 & 3.823 & 1.717 \\
P value & 0.064 & 0.037 & 0.095 & 0.006 \\
\hline
\end{tabular}

*, positive values indicate an increase in sagittal parameters and negative values indicate a decrease with one unit increase of the determinant. B, coefficient; C7T, C7 tilt; SSA, spino-sacral angle; SVA, sagittal vertical axis; LL, lumbar lordosis; mSASSS, modified Stoke Ankylosing Spondylitis Spine Score; ASspiMRI-a, Ankylosing Spondylitis spinal MRI activity.

patients was closely related to the inflammation and structural damage of the lumbar spine. The chronic inflammation caused the progressive ossification of spinal ligaments and facet joints will ultimately lead to the severe kyphotic deformities $(5,29)$. In addition, structural spinal damage contributed to the disturbance of sagittal alignments and led to thoracolumbar kyphosis and global sagittal imbalance $(8,11)$.

However, the contributions of lumbar inflammation and structural damage to the sagittal parameters in AS patients with thoracolumbar kyphosis were still unclear. To our knowledge, this was the first study focusing on the correlations between structural damage and inflammation of the lumbar spine and the sagittal imbalance in AS patients with thoracolumbar kyphosis.

The results of the current study showed that the sagittal imbalance in late AS patients with thoracolumbar kyphosis was determined by both inflammation and structural damage of the lumbar spine. Correlations between the sagittal parameters (represented by C7T, SSA, SVA, and LL) and lumbar inflammation could be used to explain the discordance between the severity of sagittal imbalance and the degree of spinal radiographic damage in AS patients with thoracolumbar kyphosis. Also, the results of the current study showed that the sagittal parameters were significantly correlated with the irreversible structural damage of the lumbar spine, which was similar to the conclusions of Wanders et al. (8), who reported that the lateral spinal flexion and BASMI discriminated best between AS patients with and without structural damage. Notably, there was no significant correlation between the sagittal 
parameters and other potential determinants, including age, gender, disease duration, BASDAI, BASFI, ODI, ESR, CRP, and HLA-B27, which was also observed in the results of Rudwaleit et al. (30) and Machado et al. (11).

Moreover, the present study demonstrated that sagittal imbalance was more likely caused by the irreversible lumbar structural damage than the reversible lumbar inflammation in AS patients with thoracolumbar kyphosis (the $\beta$ values of mSASSS were greater than ASspiMRI-a according to the multivariable regression models, as shown in Table 5). This conclusion was closely related to the findings of Machado et al. (11), who reported that spinal mobility impairment was determined to a much greater extent by structural damage ( $\beta=0.865, P<0.001)$ than spinal inflammation $(\beta=-0.305$, $\mathrm{P}=0.165)$ in AS patients with a disease duration $>3$ years.

Significantly, the long-term effects of inflammation should not be neglected since AS patients with thoracolumbar kyphosis often suffered from inflammation (all AS patients had elevated ASspiMRI-a scores in the current study). Notably, although all $\mathrm{P}$ values were $<0.05$, multivariable regression analysis found no correlation between ASspiMRI-a and C7T or SVA (Table 5). Evaluation of sagittal balance was comprehensively based on the sagittal parameters, including C7T, SSA, SVA, and LL, as reflected by our results in Table 5 . Although the multivariable regression analysis did not demonstrate a significant correlation between ASspiMRI-a and C7T or SVA ( $\mathrm{P}>0.05)$, the results did demonstrate marginal correlations between lumbar inflammation and C7T $(\mathrm{P}=0.064)$ and SVA ( $\mathrm{P}=0.095)$. Furthermore, LL was significantly correlated with C7T, SSA, and SVA (Table 4), which implied that LL might play a crucial role in determining the other three parameters. This is because LL was the basement of the upper spine and the most secondary affected area of spinal lesions in AS. In other words, LL could also partially reflect the sagittal balance status. The results in Table 4 illustrated that the ASspiMRI-a score was significantly associated with SSA and LL and was marginally correlated with C7T and SVA. Based on this and clinical practice, the proposition of lumbar inflammation being linked to the sagittal imbalance was acceptable in the present study.

Also, the present study showed that the C7T, SSA, and SVA were significantly correlated with LL $(r=-0.696$, -0.779 , and 0.633 , respectively, $\mathrm{P}<0.05$ ). The severe sagittal imbalance implied by a small C7T and SSA, and a large SVA in late AS patients was initially attributed to the significant decrease of LL. The results suggested that the decrease of LL was one of the crucial mechanisms of the global sagittal imbalance for AS patients in late stages. Similar results were also reported in previous studies $(5,9)$. Furthermore, the negative $\beta$ values of C7T and SSA indicated that lumbar inflammation was negatively correlated with C7T and SSA. C7T was verified as useful for assessing sagittal balance. With the development of sagittal imbalance, the upper trunk (including C7) shifted forward as the C7T trend decreased, which implied that the C7T was negatively correlated with sagittal imbalance. However, the lumbar inflammation was positively associated with sagittal imbalance (5). Thus, the lumbar inflammation evaluated by the ASspiMRI-a score was negatively associated with sagittal imbalance. The SSA could also be interpreted similarly. Pelvic retroversion was frequently noted in AS patients with kyphosis for regulating sagittal balance (31), which indicated that the SSA tended to decrease. Simultaneously, the line tended to incline forward along with the upper trunk shifting forward, which connected the center of the $\mathrm{C} 7$ vertebra to the midpoint of the sacral endplate and the sacral endplate. In such a condition, the SSA was naturally negatively associated with sagittal imbalance, while lumbar inflammation was positively associated with sagittal imbalance. Thus, lumbar inflammation evaluated by ASspiMRI-a score was negatively associated with SSA.

Some limitations of this study should be noted. Firstly, the mSASSS scoring system was based on syndesmophyte formation and bridging in the anterior vertebral corners, while the posterior sites and soft tissue around the spine were underestimated. The ASspiMRI-a scoring system also exhibited a similar issue; vertebral inflammation was taken into account. However, the surrounding soft tissues and facet joints were excluded. Since the mSASSS and ASspiMRI-a scoring systems were already being used in our clinic, they were applied for the current study, and no other scoring systems were utilized. However, this is unlikely to have influenced the conclusions at the group level.

Moreover, although all lumbar vertebrae were carefully assessed, the cervical and thoracic vertebrae were excluded, which presents a further limitation. This study focused on exploring the correlation between structural damage and inflammation of the thoracolumbar/lumbar spine and thoracolumbar kyphosis, the latter of which was usually accompanied by a loss of lumbar lordosis. So, the deformity is mainly developed in the thoracolumbar/lumbar spinal segments. Structural damage and inflammation of the cervical spine did not contribute to the formation of thoracolumbar kyphosis and were thus not included. Further studies evaluating the entire spine involving a 
larger cohort should be performed. Nevertheless, the correlations between structural damage and inflammation of the thoracolumbar/lumbar spine in late AS patients with thoracolumbar kyphosis were quantified by this study for the first time.

In summary, the sagittal imbalance, represented by abnormal LL, C7T, SSA, and SVA, was influenced by both structural damage and inflammation of the lumbar spine in AS patients with thoracolumbar kyphosis. The sagittal imbalance was more attributable to structural damage than inflammation of the lumbar spine in late AS patients.

\section{Acknowledgments}

We thank Yanyu Ma and Yuwen Wang for their assistance in the data analyses.

Funding: This work was financially supported by General Subjects on the Development of Medical Science and Technology in Nanjing (YKK16119).

\section{Footnote}

Conflicts of Interest: All authors have completed the ICMJE uniform disclosure form (available at http://dx.doi. org/10.21037/qims-19-990). The authors have no conflicts of interest to declare.

Ethical Statement: The Ethics Committee approved this study of The Affiliated Drum Tower Hospital of Nanjing University Medical School. Informed consent was not applicable due to the retrospective nature of this study.

Open Access Statement: This is an Open Access article distributed in accordance with the Creative Commons Attribution-NonCommercial-NoDerivs 4.0 International License (CC BY-NC-ND 4.0), which permits the noncommercial replication and distribution of the article with the strict proviso that no changes or edits are made and the original work is properly cited (including links to both the formal publication through the relevant DOI and the license). See: https://creativecommons.org/licenses/by-nc-nd/4.0/.

\section{References}

1. Braun J, Sieper J. Ankylosing spondylitis. Lancet 2007;369:1379-90.

2. Zochling J, Sieper J, van der Heijde D, Braun J, Assessment in Ankylosing Spondylitis International
Working G. Development of a core set of domains for data collection in cohorts of patients with ankylosing spondylitis receiving anti-tumor necrosis factor-alpha therapy. J Rheumatol 2008;35:1079-82.

3. Baraliakos X, Landewe R, Hermann KG, Listing J, Golder W, Brandt J, Rudwaleit M, Bollow M, Sieper J, van der Heijde D, Braun J. Inflammation in ankylosing spondylitis: a systematic description of the extent and frequency of acute spinal changes using magnetic resonance imaging. Ann Rheum Dis 2005;64:730-4.

4. Vosse D, van der Heijde D, Landewe R, Geusens P, Mielants H, Dougados M, van der Linden S. Determinants of hyperkyphosis in patients with ankylosing spondylitis. Ann Rheum Dis 2006;65:770-4.

5. Debarge R, Demey G, Roussouly P. Sagittal balance analysis after pedicle subtraction osteotomy in ankylosing spondylitis. Eur Spine J 2011;20 Suppl 5:619-25.

6. Dalyan M, Guner A, Tuncer S, Bilgic A, Arasil T. Disability in ankylosing spondylitis. Disabil Rehabil 1999;21:74-9.

7. Scott DL, Smith C, Kingsley G. Joint damage and disability in rheumatoid arthritis: an updated systematic review. Clin Exp Rheumatol 2003;21:S20-7.

8. Wanders A, Landewe R, Dougados M, Mielants H, van der Linden S, van der Heijde D. Association between radiographic damage of the spine and spinal mobility for individual patients with ankylosing spondylitis: can assessment of spinal mobility be a proxy for radiographic evaluation? Ann Rheum Dis 2005;64:988-94.

9. Debarge R, Demey G, Roussouly P. Radiological analysis of ankylosing spondylitis patients with severe kyphosis before and after pedicle subtraction osteotomy. Eur Spine J 2010;19:65-70.

10. Landewé R, Dougados M, Mielants H, van der Tempel $\mathrm{H}$, van der Heijde D. Physical function in ankylosing spondylitis is independently determined by both disease activity and radiographic damage of the spine. Ann Rheum Dis 2009;68:863-7.

11. Machado P, Landewe R, Braun J, Hermann KG, Baker $\mathrm{D}$, van der Heijde D. Both structural damage and inflammation of the spine contribute to impairment of spinal mobility in patients with ankylosing spondylitis. Ann Rheum Dis 2010;69:1465-70.

12. van der Linden S, Valkenburg HA, Cats A. Evaluation of diagnostic criteria for ankylosing spondylitis. A proposal for modification of the New York criteria. Arthritis Rheum 1984;27:361-8.

13. Pedersen SJ, Sorensen IJ, Garnero P, Johansen JS, Madsen OR, Tvede N, Hansen MS, Thamsborg G, 
Andersen LS, Majgaard O, Loft AG, Erlendsson J, Asmussen K, Jurik AG, Moller J, Hasselquist M, Mikkelsen D, Skjodt T, Lambert R, Hansen A, Ostergaard M. ASDAS, BASDAI and different treatment responses and their relation to biomarkers of inflammation, cartilage and bone turnover in patients with axial spondyloarthritis treated with TNFalpha inhibitors. Ann Rheum Dis 2011;70:1375-81.

14. van Weely SF, van Denderen JC, Steultjens MP, van der Leeden M, Nurmohamed MT, Dekker J, Dijkmans BA, van der Horst-Bruinsma IE. Moving instead of asking? Performance-based tests and BASFI-questionnaire measure different aspects of physical function in ankylosing spondylitis. Arthritis Res Ther 2012;14:R52.

15. Tonosu J, Takeshita K, Hara N, Matsudaira K, Kato S, Masuda K, Chikuda H. The normative score and the cutoff value of the Oswestry Disability Index (ODI). Eur Spine J 2012;21:1596-602.

16. Roussouly P, Pinheiro-Franco JL. Sagittal parameters of the spine: biomechanical approach. Eur Spine J 2011;20 Suppl 5:578-85.

17. Qian BP, Qiu Y, Wang B, Sun X, Zhu ZZ, Jiang J, Ji ML. Pedicle subtraction osteotomy through pseudarthrosis to correct thoracolumbar kyphotic deformity in advanced ankylosing spondylitis. Eur Spine J 2012;21:711-8.

18. Obeid I, Hauger O, Aunoble S, Bourghli A, Pellet N, Vital JM. Global analysis of sagittal spinal alignment in major deformities: correlation between lack of lumbar lordosis and flexion of the knee. Eur Spine J 2011;20 Suppl 5:681-5.

19. Du CZ, Li S, Xu L, Zhou QS, Zhu ZZ, Sun X, Qiu Y. Spinal Gorham-Stout syndrome: radiological changes and spinal deformities. Quantitative imaging in medicine and surgery 2019;9:565.

20. Mac-Thiong JM, Labelle H, Roussouly P. Pediatric sagittal alignment. Eur Spine J 2011;20 Suppl 5:586-90.

21. Shu S, Hu Z, Bao H, Shi J, Hu A, Grelat M, Liu Z, Sun X, Qian B, Cheng JC. An analysis of the interactions between the spine, pelvis, and lower limbs in asymptomatic adults with limited pelvic compensation. Quant Imaging Med Surg 2020;10:999.

22. Creemers MC, Franssen MJ, van't Hof MA, Gribnau FW, van de Putte LB, van Riel PL. Assessment of outcome in ankylosing spondylitis: an extended radiographic scoring system. Ann Rheum Dis 2005;64:127-9.

23. Braun J, Baraliakos X, Golder W, Brandt J, Rudwaleit M, Listing J, Bollow M, Sieper J, Van Der Heijde D. Magnetic resonance imaging examinations of the spine in patients with ankylosing spondylitis, before and after successful therapy with infliximab: evaluation of a new scoring system. Arthritis Rheum 2003;48:1126-36.

24. Lukas C, Braun J, van der Heijde D, Hermann KG, Rudwaleit M, Ostergaard M, Oostveen A, O'Connor P, Maksymowych WP, Lambert RG, Jurik AG, Baraliakos $\mathrm{X}$, Landewe R, Group AOMiAW. Scoring inflammatory activity of the spine by magnetic resonance imaging in ankylosing spondylitis: a multireader experiment. J Rheumatol 2007;34:862-70.

25. Sieper J, Baraliakos X, Listing J, Brandt J, Haibel H, Rudwaleit M, Braun J. Persistent reduction of spinal inflammation as assessed by magnetic resonance imaging in patients with ankylosing spondylitis after 2 yrs of treatment with the anti-tumour necrosis factor agent infliximab. Rheumatology (Oxford) 2005;44:1525-30.

26. Arun R, Dabke HV, Mehdian H. Comparison of three types of lumbar osteotomy for ankylosing spondylitis: a case series and evolution of a safe technique for instrumented reduction. Eur Spine J 2011;20:2252-60.

27. Zhu Z, Wang X, Qian B, Wang B, Yu Y, Zhao Q, Qiu Y. Loss of correction in the treatment of thoracolumbar kyphosis secondary to ankylosing spondylitis: a comparison between Smith-Petersen osteotomies and pedicle subtraction osteotomy. J Spinal Disord Tech 2012;25:383-90.

28. Chang KW, Cheng CW, Chen HC, Chang KI, Chen TC. Closing-opening wedge osteotomy for the treatment of sagittal imbalance. Spine (Phila Pa 1976) 2008;33:1470-7.

29. Kiaer T, Gehrchen M. Transpedicular closed wedge osteotomy in ankylosing spondylitis: results of surgical treatment and prospective outcome analysis. Eur Spine J 2010;19:57-64.

30. Rudwaleit M, Schwarzlose S, Hilgert ES, Listing J, Braun J, Sieper J. MRI in predicting a major clinical response to anti-tumour necrosis factor treatment in ankylosing spondylitis. Ann Rheum Dis 2008;67:1276-81.

31. Qian BP, Jiang J, Qiu Y, Wang B, Yu Y, Zhu ZZ. The presence of a negative sacral slope in patients with ankylosing spondylitis with severe thoracolumbar kyphosis. J Bone Joint Surg Am 2014;96:e188.

Cite this article as: $\mathrm{Li} \mathrm{S}$, Du CZ, Mao SH, Shi BL, Zhu ZZ, Qiu Y. Both structural damage and inflammation of the lumbar spine contribute to the sagittal imbalance in ankylosing spondylitis patients with thoracolumbar kyphosis. Quant Imaging Med Surg 2021;11(1):362-370. doi: 10.21037/ qims-19-990 